\title{
The Use of Phage to Study Causes of Loss of Viability of Escherichia coli in Aerosols
}

\author{
By C. S. COX AND F. BALDWIN \\ Microbiological Research Establishment, Porton Down, near Salisbury, Wiltshire
}

(Received 20 October 1965)

\begin{abstract}
SUMMARY
This paper presents data to show that loss of viability of Escherichia coli and phage in an aerosol was the consequence of at least three mechanisms. Phage T 7 was used and shown to be unstable when sprayed into air. When previously adsorbed to $\boldsymbol{E}$. coli the aerosol stability of phage T7 appeared to be dependent upon its stage of development in its host. The host $E$. coli strain B in an aerosol was itself subject to two stresses which operated through different mechanisms within the bacterium: (i) a relative humidity stress having its locus of action such that colony formation and the production of phage $\mathbf{T r}$ were both impaired; (ii) an air stress such that colony formation was impaired but that the bacterium was able to produce phage $\mathbf{T r}$.
\end{abstract}

\section{INTRODUCTION}

Investigations (Cox, 1966) have shown that the survival of bacteria in an aerosol depends upon a number of factors. In assessing degree of survival the usual test for deciding whether bacteria are alive or dead depends upon the appearance of visible colonies on an agar plate, but this method does not allow a determination of the cause of death. The use of a suitable phage (Cox \& Baldwin, 1964) enables a distinction to be made between death resulting from breakdown of the phage productive capacity of a bacterium (measured as its ability to produce phage) and from loss of the reproductive capacity of the bacterium (reactions other than those involved in phage production). By using the following scheme, deductions can be made as to which capacities have been damaged by the processes involved in aerosol experiments :

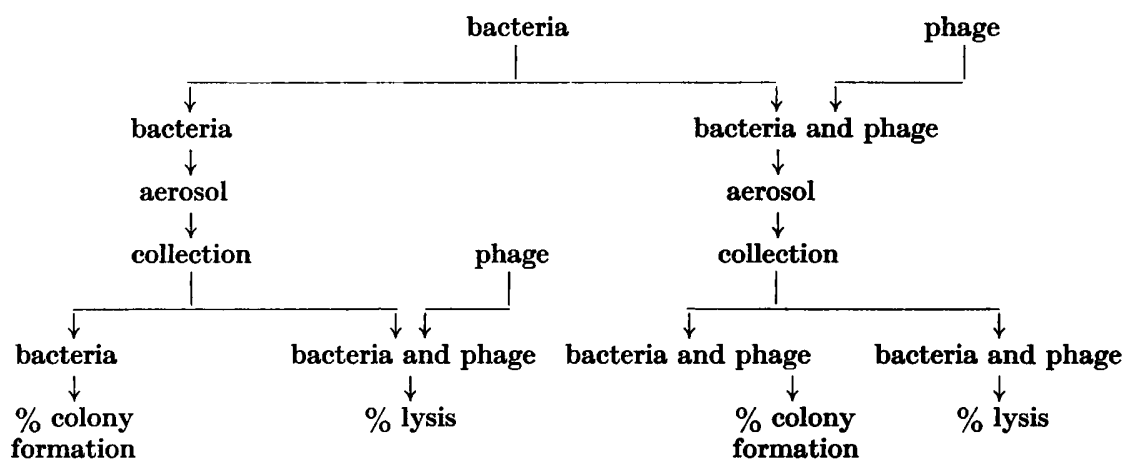


For example, two simple cases can be considered.

(i) When the bacterium loses reproductive capacity only, then colony formation will be less than $100 \%$. However, the ability of these bacteria to produce phage will be unaffected and provided that an aerosol-stable phage is used, subjecting the bacteria to phage after or before 'aerosolization' and collection will result in all of the bacteria undergoing lysis.

(ii) When the bacterium loses phage productive capacity only, then the ability to form colonies and to produce phage will be equally affected. Values will be the same for $\%$ colony formation and \% lysis for bacteria infected with phage after collection. This will also be so for bacteria infected with phage before aerosol formation, provided that an aerosol-stable phage is used and provided that no phage development is allowed to occur before aerosol formation. This paper presents data obtained by the application of these techniques.

\section{METHODS}

Organisms. Cultures of Escherichia coli strain B, were grown in a $2 \%$ tryptone medium ( $\mathrm{pH} 7 \cdot 2$ ) for $16 \mathrm{hr}$ at $37^{\circ}$ in shaken flasks. Coliphage $\mathrm{T} 7$ was prepared in a conventional manner by inoculating a log-phase culture of $E$. coli B with phage $\mathbf{T} 7$ and allowing the suspension to clear. Centrifugation removed unlysed bacteria.

Suspensions of bacteria and phage. Two types of suspension were used. Type 1 suspensions were of Escherichia coli в infected with phage $\mathbf{T} 7+$ Bacillus subtilis var. niger spores. The spores were added so that allowance could be made for physical loss of aerosol particles (Harper, Hood \& Morton, 1958). The suspensions of $E$. coli B were prepared by separating bacteria of the $16 \mathrm{hr}$ culture from the culture medium by centrifugation. These bacteria were re-suspended at $37^{\circ}$ in aerated tryptic meat broth, containing 0.004 $\mathrm{M}$-potassium cyanide. After $2 \mathrm{~min}$. phage $\mathrm{T} 7 \mathrm{was}$ added in an amount which depended upon the required ratio of phage to bacteria. The mixture was shaken and maintained at $37^{\circ}$ for $10 \mathrm{~min}$. to allow phage adsorption and injection of phage DNA. After this time bacteria and free phage were separated by centrifugation, the bacteria being re-suspended in tryptic meat broth. For those experiments in which phage development was allowed to occur before aerosolization, the resuspended bacteria in tryptic meat broth were maintained at $37^{\circ}$ for the required time and then were rapidly chilled. Following this, tracer spores of $B$. subtilis var. niger in tryptic meat broth were added and the suspension aerosolized immediately. A control suspension differing only in that tryptic meat broth replaced the phage suspension was similarly prepared.

Type 2 suspensions were prepared by centrifuging down bacteria from culture fluid, washing them in glass-distilled water, re-centrifuging and suspending in glass-distilled water. Type 2 suspensions, without tracer spores, were used in experiments for estimating \% lysis of bacteria infected with phage $\mathrm{T} 7$ after collection from the aerosol.

Aerosol storage. A rotating drum apparatus was used, as described by Cox, (1966).

Aerosol collection and assay. Type 1 suspension. Samples were collected in raised impingers (May \& Harper, 1957) at $0.3 \mathrm{sec}$., $3 \mathrm{sec}$., $2 \mathrm{~min} ., 15 \mathrm{~min}$. and $30 \mathrm{~min}$. aerosol ages. The phage-infected bacteria were assayed by plaque formation at $37^{\circ}$ in freshly prepared media of soft tryptic meat $0.5 \%$ agar layered on to a $1 \%$ tryptone agar, and the bacillus spores were assayed on $1 \%$ tryptone agar at $37^{\circ}$ 
(Miles \& Misra, 1938). Each sample was assayed on six plates, and the ratio of the number of plaques to the number of Bacillus subtilis var. niger colonies per sample was used to calculate \% lysis, based on the ratio in the spray fluid as being $100 \%$. Percentage survival of the control phage-free bacteria was measured as for $\boldsymbol{B}$. subtilis var. niger. Since Escherichia coli $\mathrm{B}$ formed white colonies and $\boldsymbol{B}$. subtilis var. niger formed orange colonies differential counting was possible.

Type 2 suspension. Samples were collected directly on to Postgate chambers (Postgate, Crumpton \& Hunter, 1961) containing $1 \%$ tryptone agar, by means of a slit sampler (Bourdillon, Lidwell \& Thomas, 1941). Percentage colony formation was calculated by observing the proportion of the total number of bacteria per microscope field which formed microcolonies at $37^{\circ}$. At least six fields per sample were examined under the microscope before growth began, and at intervals these same fields were observed for $4 \frac{1}{2} \mathrm{hr}$.

The \% lysis was determined by collecting bacteria on to Postgate chambers (Postgate et al. 1961) previously inoculated with phage $\mathrm{T} 7$ and observing the proportion of the initial number of bacteria per microscope field which lysed. Other details were as for $\%$ colony formation. Included in the assay were the $\%$ lysis (usually 100) and \% colony formation values for unsprayed bacteria taken from the type 2 suspension.

Samples were also collected in raised impingers (May \& Harper, 1957) at times as for a type 1 suspension. Since no tracer spores were present, physical decay was assumed to be as for experiments reported by Cox (1966).

\section{RESULTS}

Experiments with Escherichia coli strain $\mathrm{B}$ infected with phage $\boldsymbol{T} \boldsymbol{Y}$ before aerosol formation in air at $23^{\circ}$ and $50 \%$ relative humidity

A type 1 suspension of Escherichia coli $\mathrm{B}$, prepared and assayed as described, gave the results shown in Fig. 1. Development times greater than 12 min. were not used since the latent period of phage $\mathrm{T} 7$ at $37^{\circ}$ was $15 \mathrm{~min}$. (Fig. 2). The highest value of $\%$ lysis was obtained at $12 \mathrm{~min}$. but did not exceed the value of bacterial survival. Increasing the phage:bacteria ratio to 10:1 gave even less satisfactory results (Fig. 3). The results showed two things. (i) Phage Tr stability was increased by adsorption to bacteria even when no development was allowed to occur. For zero development time initial values for $\%$ lysis of $9 \%$ (Fig. 1) and $6 \%$ (Fig. 3) contrast with $\mathbf{0} \cdot \mathbf{4} \%$ survival of phage $\mathrm{T} 7$ when sprayed alone from the same medium. (ii) Since $\%$ survival of bacteria was invariably greater than $\%$ lysis, loss of viability of $\boldsymbol{E}$. coli B was not responsible for the inability of phage $\mathbf{T} \boldsymbol{7}$ to mature and form plaques.

Included in Figs. 1 and 3 are the arithmetic means of the \% survival values and the standard deviations for the control experiments conducted with non-infected bacteria. The magnitude of the standard deviations, especially for the $\mathbf{3 0} \mathrm{min}$. aerosol age samples, may have been because, as the development time for the phagefree control bacteria increased, so the degree of Escherichia coli в survival decreased. This was confirmed in that for a $40 \mathrm{~min}$. development time for $\boldsymbol{E}$. coli $\mathrm{B}, 5 \%$ survival was obtained at an aerosol age of $30 \mathrm{~min}$. as compared to $49 \%$ survival for zero development time. 
To stabilize phage $\mathrm{T} 7$ to a greater degree than that described above, the procedure for obtaining phage-infected bacteria needed to be modified. A suspension of $16 \mathrm{hr}$ Escherichia coli B in aerated tryptic meat broth at $37^{\circ}$ was prepared without cyanide and this suspension was inoculated with phage $\mathbf{T} 7$ to give a ratio of phage: bacteria of 10:1. For the next $10 \mathrm{~min}$. the suspension was allowed to cool while adsorption and phage development occurred. After $10 \mathrm{~min}$. the suspension was centrifuged to remove unadsorbed phage and the deposited infected bacteria were resuspended in tryptic meat broth at room temperature. Such infected bacteria gave $100 \%$ lysis after $30 \mathrm{~min}$. in the aerosol, as previously reported (Cox \& Baldwin, 1964). Electron micrographs of these bacteria showed that complete maturation of phage had not occurred.

These results suggest that the aerosol stability of phage $\mathbf{T} 7$ inside the bacteria critically depended upon the state of development of the phage.

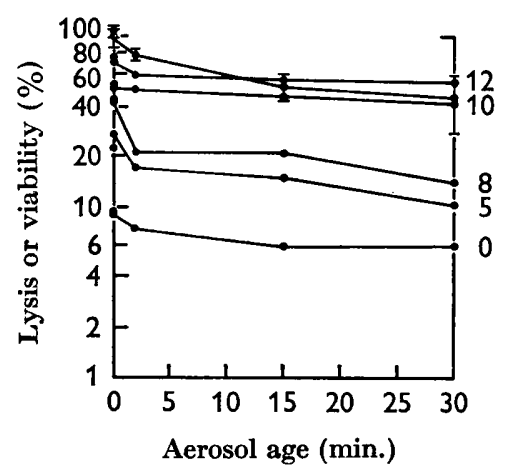

Fig. 1

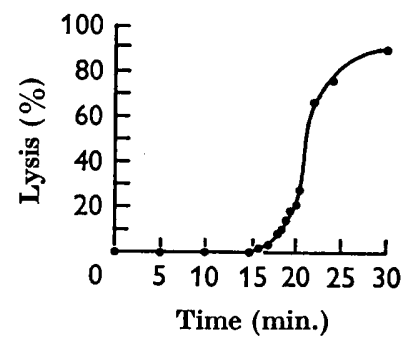

Fig. 2

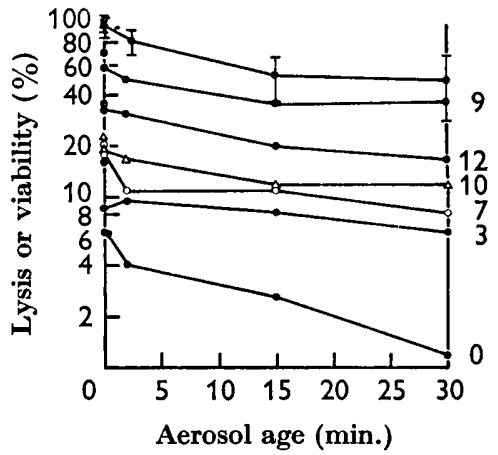

Fig. 3

Fig. 1. Aerosol survival of phage Try as a function of development time (min). in Escherichia coli strain $\mathbf{B}$. Temperature $23^{\circ}$. Phage: bacteria ratio of $1: 1$.

Fig. 2. Latent period of phage $\mathrm{T} 7$ at $37^{\circ}$; host Escherichia coli strain B.

Fig. 3. Aerosol survival of phage $\mathrm{Tr}$ as a function of development time (min.) in Escherichia coli strain B. Temperature $23^{\circ}$. Phage: bacteria ratio of 10:1.

\section{Experiments with Escherichia coli strain $\mathrm{B}$ infected with phage $\mathrm{T} 7$ before and after collection from air at $23^{\circ}$ and $50 \%$ relative humidity}

A type 1 suspension (phage: bacteria ratio of $5: 1$ ) without Bacillus subtilis var. niger spores was prepared, allowing zero development time. After aerosol formation samples were collected at $\mathbf{0} \cdot 05,1$ and $15 \mathrm{~min}$. by raised impinger (May \& Harper, 1957) and at $15 \mathrm{~min}$. only by slit sampler (Bourdillon, Lidwell \& Thomas, 1941) on to phage-free and phage-treated Postgate chambers (Postgate et al. 1961). The principle of the experiment was that if only inactivation of the phage occurred, then after collection the phage-infected bacteria should form colonies, and also support phage growth when re-infected. The results of the experiment, including the aerosol survival of a phage-free control, are given in Table 1. The data suggest the following conclusions. (a) Since only $28 \%$ of bacteria infected with phage T 7 before aerosol formation were able to lyse after collection, then $72 \%$ of these bacteria as a result of aerosolization and collection developed a condition which prevented phage $\mathbf{T} 7$ growth. Samples collected by impinger show that this condition quickly developed 
and that, concomitant with loss of ability to lyse was the appearance of colonies $(53 \%)$, i.e. bacteria forming phage plaques before aerosol formation became colony producers as a result of aerosolization and collection. $(b)$ The $\%$ colony formation of uninfected bacteria was $50 \%$, yet $61 \%$ of bacteria lysed when infected with phage T7 after collection; therefore $11 \%$ of the bacteria must have had an impaired bacterial reproductive capacity. $(c)$ Following re-infection by phage $\mathrm{T} 7$ of bacteria infected with this phage before aerosol formation, only $61 \%$ were able to lyse. Hence $39 \%$ of these bacteria must have had an impaired phage productive capacity. The results given in Table 1 were therefore the consequence of at least one mechanism responsible for loss of viability of phage $\mathrm{Tr}$ and two mechanisms for Escherichia coli в.

Table 1. Percentage lysis for Escherichia coli strain в infected with phage T7 before spraying and after aerosol collection, and \% colony formation

Type 1 suspension of $E$. coli B infected with phage $T \boldsymbol{T}$ (phage:bacteria ratio of 5:1) sprayed from culture medium into air at $50 \%$ relative humidity and $\mathbf{2 3}^{\circ}$

\begin{tabular}{|c|c|c|c|c|c|c|}
\hline $\begin{array}{l}\text { Aerosol } \\
\text { age } \\
\text { (min.) }\end{array}$ & $\begin{array}{l}\% \text { colony } \\
\text { formation* } \\
\text { of control }\end{array}$ & \% lysis $\dagger$ & $\begin{array}{l}\% \text { colony } \\
\text { formation } \ddagger\end{array}$ & $\begin{array}{l}\% \text { colony } \\
\text { formation } \ddagger\end{array}$ & $\%$ lysis $\uparrow$ & \% lysis§ \\
\hline 0 & 100 & 96 & 4 & - & - & - \\
\hline 0.05 & 100 & 4 & 53 & - & - & - \\
\hline 1 & 100 & 6 & 41 & - & - & - \\
\hline 15 & $\mathbf{5 0}$ & 4 & 23 & $\mathbf{9}$ & 28 & 61 \\
\hline Collector & & Impinger & & & lit sample & \\
\hline
\end{tabular}

$* \%$ colony formation $=\%$ colony formation of phage-free control.

$\dagger \%$ lysis $=\%$ lysis of bacteria infected with phage before aerosol formation.

$\ddagger \%$ colony formation (owing to death of phage) $=\%$ colony formation of bacteria injected with phage before aerosol formation.

$\S \%$ lysis (owing to death of phage) $=\%$ lysis of bacteria reinfected with phage before aerosol formation.

Experiments with Escherichia coli strain в infected with phage T7 after collection of an aerosol stored in nitrogen or air at various relative humidities

Other work has shown (Cox, 1966) that three stresses could influence the survival of Escherichia coli in the aerosol, namely, an air stress, a relative humidity stress and a collection stress. Of these, the first and second were investigated by using phage $\mathbf{T} 7$ in an attempt to demonstrate the locus of action of the stresses. Bacterial suspensions type 2 were prepared with a spray fluid of distilled water and were aerosolized into atmospheres of nitrogen $(>99.9 \%$ ) or air at several values of relative humidity. Percentage colony formation and \% lysis values are given in Table 2 for an aerosol age of $\mathbf{3 0} \mathrm{min}$. The \% colony formation is represented by two values, that in normal type is the \% actually dividing, while the values in bold type include bacteria which showed swelling or filamentous growth but did not divide during the period of observation. The large difference in the two values at low, but not at high, relative humidity, suggest that the process of cell division may have been slightly impaired at low relative humidity. The results also show that the relative humidity stress and the air stress operated at different loci of the bacteria. 
Table 2. Escherichia coli strain B. $\%$ colony formation and $\%$ lysis values for aerosol samples subjected to phage $T 7$ after collection

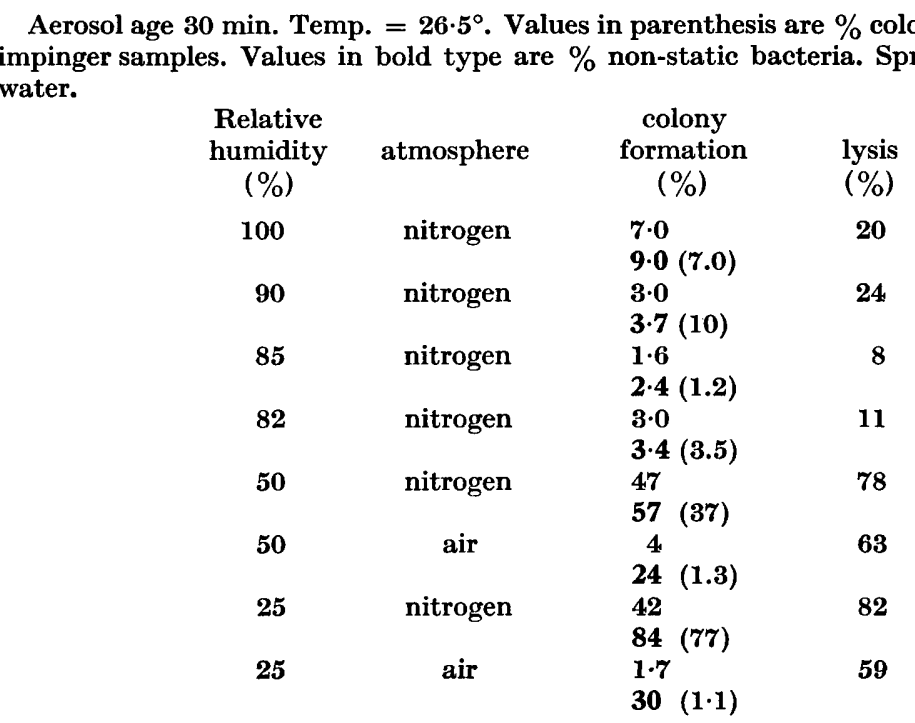

\section{DISCUSSION}

Causes of death of phage $T \%$. Phage $T 7$ was not stable as an aerosol when sprayed in the free state. When allowed to infect a suspension of Escherichia coli в without permitting development of the phage to occur, nearly $100 \%$ plaques were produced; but after aerosol generation, storage and collection, many of the bacteria were able to form colonies and were also capable of supporting phage $\mathrm{T} 7$ growth upon reinfection. It would seem then, that phage Tr DNA became biologically inactivated at $50 \%$ relative humidity in times comparable to those for droplet evaporation. If phage infection had not occurred, then damage to the process of infection is likely to have produced the observed result. DNA inactivation would also account for the results (Figs 1, 3) when phage $\mathbf{T} 7$ development was allowed to occur before aerosol formation. If this explanation is correct then phage T 7 DNA can be inactivated in the aerosol and its inherent stability can be increased by allowing the phage to develop to a certain degree; a similar result was found by Webb, Dumasia \& Singh Bhorjee (1965). The actual processes responsible for enhancing the stability are unknown, but would appear to be of two kinds: (i) processes involved during phage adsorption and injection of phage DNA; (ii) processes which occur late in phage T 7 development.

Causes of death of Escherichia coli в. Collected bacterial aerosol samples did not show $100 \%$ colony formation, and did not produce $100 \%$ lysis when infected with phage $\mathrm{T} 7$ after collection. Provided that phage adsorption and infection processes are not impaired, the difference between colony formation and $\%$ lysis represents the $\%$ of bacteria with an impairment which occurs off the phage production pathway, i.e. the $\%$ with an impaired bacterial reproductive capacity. The difference between $\%$ lysis and $100 \%$ represents the bacteria with an impairment on a path- 
way common to the reproduction of bacteria and the production of phage, i.e. an impaired phage productive capacity. At high and low relative humidities for aerosols in atmospheres of nitrogen (Table 2) the main reason for loss of bacterial viability is an impaired phage productive capacity. At intermediate relative humidities for aerosols in atmospheres of nitrogen the results suggest that loss of bacterial viability is the result of impaired phage productive and bacterial reproductive capacities. Therefore the degree and the nature of impairment is related to the relative humidity. For the conditions tested the degree of impairment of phage productive capacity appeared to be greatest at $85 \%$ relative humidity.

For aerosols in air (Table 2 ) at relative humidity values other than those at which a substantial impairment of phage productive capacity occurs, the main cause of loss of bacterial viability was through an impaired bacterial reproductive capacity. For aerosols in air at relative humidity values (e.g. $85 \%$ ) where substantial impairment of phage productive capacity occurs, then loss of viability of Escherichia coli B was mainly from an impaired phage productive capacity. If the adsorption processes of phage were impaired when bacteria collected from the aerosol were subjected to phage, then the argument is similar to that presented above except that the loss of $\boldsymbol{E}$. coli B viability attributed to loss of phage productive capacity is now attributed to an impairment of phage adsorption processes, the degrees of which are related to the loss of bacterial viability caused by loss of bacterial reproductive capacity. A combination of the two postulates is possible, in that the difference between $\%$ lysis and $100 \%$ can be attributed to loss of phage productive capacity together with some impairment of the adsorption processes of phage multiplication.

By using an aerosol-stable phage it should be possible to determine the position in the phage productive pathway at which impairment of bacterial viability occurs through aerosol formation, storage and collection. The procedure would be to use different development times prior to aerosol formation and determine the development time required to give $100 \%$ lysis. Provided that sufficient is known about the timing of the stages of phage development then the position of the impairment in the metabolic pathway of Escherichia coli в could be determined.

We thank Mr I. H. Silver for his interest and encouragement during this work. Our thanks are due to Mr W. J. Harris for preparing electron micrographs and to Mr M. C. Aireton and Mr A. D. Grandfield for technical assistance.

\section{REFERENCES}

Bourdillon, R. B., Lidwell, O. M. \& Thomas, J. C. (1941). A slit sampler for collecting and counting airborne bacteria. J. Hyg., Camb. 41, 197.

Cox, C. S. (1966). The survival of Escherichia coli atomized into air and into nitrogen from distilled water and from solutions of protecting agents, as a function of relative humidity. J. gen. Microbiol. 43, 383.

Cox, C. S. \& Baldwin, F. (1964). A method for investigating the cause of death of airborne bacteria. Nature, Lond. $202,1135$.

Harper, G. J., Hood, A. M. \& Morton, J. D. (1958). Airborne microorganisms; a technique for studying their survival. J. Hyg., Camb. 56, 534.

MAY, K. R. \& HARPER, G. J. (1957). The efficiency of various liquid impinger samplers in bacterial aerosols. Br. J. indust. Med. 14, 187. 
Mines, A. A. \& Misra, S. S. (1938). Estimation of the bactericidal power of blood. J. Hyg., Camb. 38, 732.

Postgate, J. R., Crumpton, J. E. \& Hunter, J. R. (1961). The measurement of bacterial viability by slide culture. J. gen. Microbiol. $24,15$.

Webi, S. J., Dumasia, M. D., \& Singh BhorJee, J. (1965). Bound water, inositol, and the biosynthesis of temperate and virulent bacteriophages by air-dried Escherichia coli. Can. J. Microbiol. 11, 141. 